\title{
Structural Equation Modelling of Labor Productivity in the Nigeria Construction Industry
}

\author{
Dorcas Bamitale Oluyemi-Ayibiowu ${ }^{1}$, Victor Adeola Adesina ${ }^{2}$ \\ ${ }^{1,2}$ Department of Civil Engineering, Federal University of Technology, Akure, Ondo State, Nigeria
}

\begin{abstract}
The high rate of construction project abandonment in Nigeria had led researches into developing means of enhancing project performance. This research developed a structural equation model of labour productivity in Nigeria building industry. To develop this model, questionnaire survey was carried out among five hundred (500) stakeholders in the building construction industry. The labour productivity factors were divided into six (6) major categories which are the Management and control (MC), Workforce(W), Material \& Equipment (ME), Finance(F), Project(P), External(E). A structural equation model was developed to show how each of the labour productivity factors influence construction project performance in terms of cost, time and quality. The result showed the Management and Control to have the highest influence on project performance with high coefficients of $0.88(88 \%)$. Further validation of the model showed MC, W and ME to be highly significant as their worse construction scenario produced a high prediction of overruns in project cost, time and quality. This research showed that a solid management, workforce and material logistics structure is key to consistent productivity that enhances good project performance in the Nigeria construction industry.
\end{abstract}

Keywords: Labor Productivity, Construction, Structural Equation Modelling, Cost, Time, Quality

\section{INTRODUCTION}

$I^{2}$ n Nigeria, the building industry stands out as the most visible contributor to capital formation. It accounted for around $40 \%$ of total capital formation in the pre-independence decade, while it contributed slightly more than $50 \%$ in the early post-independence decade[1]. Nigeria's construction industry is labor-intensive, and it employs the majority of the country's workforce. In addition, the industry controls more than half of the nation's Gross National Product. In most developing countries, the sector is also regarded as a gauge for the economy's performance. Sadly, most empirical research have found that the industry's output is quite poor when compared to that of several industrialized countries [1].

A country's capability to improve its national output growth over time depends almost entirely on the size and productivity of its labor force. In Nigeria, labor productivity growth has been unsatisfactory [2]. Indeed, there is a huge decline in GDP per worker over the years, with the labor productivity in the manufacturing and construction subsectors experiencing a decline by 23.59 and 22.53 percent respectively between 2011 and 2016 [3]. The prevailing harsh economic climate in the country has made productivity to be at low ebb leading to a myriad of problems ranging from prohibitive cost of construction to wide discrepancies between planned and actual construction duration, sometimes leading to outright abandonment of the project [4].People, however, continue to construct even during periods of economic hardship. The government, as the main client, continues to engage in capital projects as a means of reviving the economy. Construction receives the highest percentage of investment capital in all developing countries. There is now a larger need to properly manage the labor force in order to deliver projects on time, on budget, and with high quality. For optimal output under the current environmental conditions, a better and more recent understanding of all aspects affecting construction labor productivity is required.

\section{LITERATURE REVIEW}

A task that demands the exertion of both the body and the mind is referred to as labor. Labor is also seen as a valuable resource in the construction industry because it is the one who brings together all of the other resources, such as materials, plant equipment, and financing, to generate the various building products as defined by [1]. However, all contracting companies must solve productivity challenges in order to obtain the full economic worth of labor. Productivity, on the other hand, is a broad measure of performance that takes efficiency into account [1].Productivity, according to Attar et al. [5], is defined as the measurement of how successfully an individual entity uses available resources to produce outputs from inputs.In general, labor productivity is the same as the "average product of labor" (average output per worker or per worker-hour, an output which could be measured in physical terms or in price terms). It's a volume measure of output divided by a volume measure of inflow. Hours worked, workforce jobs, and the number of individuals employed are the three most regularly utilized input measures. i.e., Labour Productivity $=$ Output/(Labour cost) or Output/(Work hour) or its inverse, Work hour/(Output), is a common contractor metric.

Labor productivity is influenced by both external and internal factors.External factors, which are those that are beyond the control of the company's management, and internal factors, which are those that originate within the organization. Low salaries, a lack of resources, and an unfavorable working environment are among the issues affecting craftsmen's output 
in Nigeria, according to a study [6]. Non-productive or down time will result from late delivery of materials or personnel, equipment breakdowns, inadequate work plan layout, and inability to supply information. Reworks, degree of competence and experience of the personnel, suitability of method of construction, buildability concerns, and poor supervision and coordination were the restrictions having the greatest influence on productivity in New Zealand, according to Durdyev and Mbachu [7].

Models that explain a variable in terms of others are frequently required, hence there are dependent and independent variables in a mathematical model. Regression approaches can be used to alter a predictive model when these variables are continuous, quantifiable, or categorized. If these dependent and independent variables are made up of other variables, they are referred to as latent constructs or dimensions, and their analysis necessitates the use of more advanced methodologies. Structural equation modeling (SEM) is one method for linking these constructs or latent variables [8].Structural equation modeling is a multivariate statistical analysis tool for analyzing structural links between measurable and latent components. This method combines factor analysis and multiple regression analysis, and it is chosen by researchers because it estimates several and interconnected dependencies in a single analysis. The introduction and development of SEM was recognized as a significant statistical development, and it has been widely used in various disciplines for theoretical investigations and empirical validations [9].There are two sorts of variables in structural equation models: latent or unobserved variables and manifest or observed variables. Variables that cannot be measured directly but can be represented or measured by one or more observable variables are known as latent or unobserved variables. Business efficiency, productivity, and worker personality are some examples of this type of variable or construct in industry. Observed or manifest variables are values that are used as a gauge of a latent variable that cannot be directly assessed. A latent variable can be made up of two or more observed variables. SEM, according to Lei and Wu [10], involves a variety of statistical techniques such as factor analysis, path analysis, and regression. Two models are evaluated using these statistics: a measurement model and a path model.The suitability of each observed/manifest variable as indicators for the latent/unobserved variables that they are designed to assess is evaluated by the measurement model. A path model is a statistical method that is based on numerous regressions. It entails the estimation of numerous multiple regression models at the same time. This makes modeling mediation, indirect effects, and other complex interactions between variables more effective and straightforward.

\section{PREVIOUS RESEAARCH ON FACTORS INFLUENCING PRODUCTIVITY}

Kazaz et al. [15] found 37 characteristics and divided them into four categories: organizational, economic, physical, and socio-physiological. Analyze the factor dispersion within a group as well as the compactness of each factor group. The findings revealed that the organizational factors group has the greatest weighted mean and lowest standard deviation values, making it the most significant. Raj et al. [11] concentrated on human resource management in the sector of construction. They conduct a questionnaire study of 100 workers from various companies. In addition, the impact of human resource management strategies on the construction industry's productivity and financial performance was investigated. They found that $75 \%$ of participants agree that site congestion causes them to work in an uncomfortable manner.Shashank et al. [12] classified factors affecting labor productivity into six categories: motivation, manpower, material/equipment, safety, managerial, and quality. They found that the motivation component has the greatest impact on labor productivity.

\section{METHODOLOGY}

\section{A. RESEARCH STUDY AREA}

Lagos State was chosen as the subject area for this research in Nigeria. This decision was based on the fact that the state has a disproportionately significant share of the country's building operations. Lagos State is located in the Federation's southwestern corner. It is located between the latitudes of $6^{\circ} 27.14 .65 \mathrm{~N}$ and $3^{\circ} 23.40 .81 \mathrm{E}$. On the north and east, it shares borders with Ogun State, and on the west, it shares borders with the Republic of Benin. It spans for 180 kilometers along the Atlantic Ocean's shore in the south. It covers 3,577 square kilometers. With an estimated population of 9,019,534, 22 percent of the land is made up of lagoons and creeks. Lagos is a hub for businesses in a variety of areas, including consulting, manufacturing, construction, oil and gas, agricultural, telecom, marketing, legal, and health.According to recent estimates by [13] on expected housing provisions for all states in the country, Lagos has the greatest prediction of $350,000,550,000,580,000$, and 750,000 housing units for the years 1991-1995, 1995-2000, 2005-2010, and 2010-2015. As a result of the aforementioned factors, as well as growing globalization in business and finance, Lagos state is seeing a surge in construction activity. [14]. Fig. 1 showed the map of the study area. 


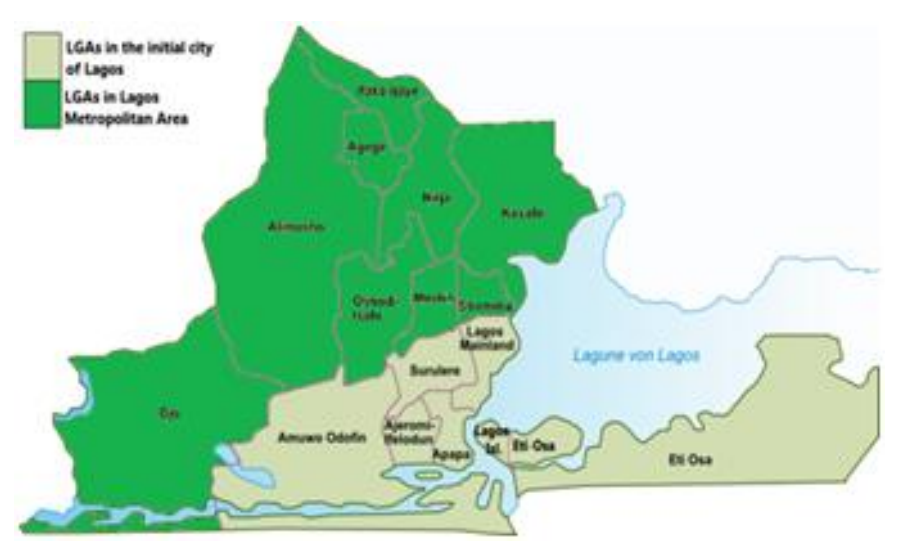

Fig. 1: Map Showing the Study Area (Lagos)

\section{B QUESTIONNAIRE DEVELOPMENT}

Supplementary data was collected via a questionnaire. There are two (2) sections to the questionnaire. The demographic part, which contained the information provided by the respondents, and the respondent analysis portion, which comprised the responses provided by the respondents. A total of 39 elements that influence productivity in Nigeria construction projects were identified at the outset and were divided into six (6) groups. Each respondent was asked to rate the amount to which each component influences labor productivity using a five-point Linkert scale which are; Strongly influence with rating of 5, little influence with rating of 4, May or may not influence with rating of 3, No influence with rating of 2 , Virtually no influence with rating of 1 . A total of five hundred (500) questionnaires were distributed to randomly selected respondents (contractors, consultants, site engineer, project managers, sub-contractors and client), four hundred and forty (440) valid responses were collected and analyzed. Fig. 2 shows the flowchart of the labor productivity influencing factors

\section{EXPLORATORY FACTOR ANALYSIS (EFA)}

EFA was used to examine the relationships between correlated variables and, if appropriate, to condense the data. This aids in the confirmation and formation of the baseline model structure for labor productivity factor structural modeling. The principal component matrix is frequently rotated for ease of comprehension of the variables recovered with varimax being the most popular of the various rotation algorithms available in SPSS. As a result, the goal of this approach was to rotate variables (factors) so that the variation of the squared variable (factor)loadings is enlarged, making it easier to comprehend the loadings based on their significance. Factors having a loading below 0.40 (cut-off for significance) were deemed to be weak predictors of the constructs due to the small sample size and were therefore excluded from the components that would make up the baseline model for the SEM Analysis.

\section{STRUCTURAL EQUATION MODEL ANALYSIS}

The SEM Analysis was performed using the AMOS Statistical software package. It consists of two components: a measurement model and structural model. The exploratory factor analysis provides the measurement model which serves as the baseline model/path for the structural model to be performed by the AMOS software.

\section{RESULT AND DISCUSSION}

Unlike regression analysis that produces different coefficients of independent variables for each dependent variable, structural equation modelling has the advantage of producing the same coefficients of independent variables for each dependent variables by making use of the path diagram/baseline model. Fig.3 showed the flowchart for the final baseline model while fig. 4 showed the resulting structural equation model.

From fig. 4, the SEM model for cost, time and quality can be deducted as follows:

Cost $=-88+0.85 \mathrm{MC}+0.76 \mathrm{~W}+0.69 \mathrm{ME}+0.67 \mathrm{~F}+0.45 \mathrm{P}+$ $0.38 \mathrm{E}$

Time $=-85+0.85 \mathrm{MC}+0.76 \mathrm{~W}+0.69 \mathrm{ME}+0.67 \mathrm{~F}+0.45 \mathrm{P}+$ $0.38 \mathrm{E}$

Quality $=-83+0.85 \mathrm{MC}+0.76 \mathrm{~W}+0.69 \mathrm{ME}+0.67 \mathrm{~F}+0.45 \mathrm{P}+$ $0.38 \mathrm{E}$

Where

$\mathrm{MC}=$ Management \& control

$\mathrm{W}=$ Workforce

$\mathrm{F}=$ Finance

$\mathrm{P}=$ Project

$\mathrm{E}=$ External

$\mathrm{ME}=$ Material \& Equipment.

From the model, Management and Control (MC) had the highest coefficient, which made it a very important labour productivity factor. This was followed by the workforce and the material and equipment..

The result showed that if a good management, workforce and material logistics structure would always enhance project performance and increases productivity no matter the circumstances of the other factors. This trait is peculiar to the big construction firms and it serves as an indicator to the capability of the model to accurately simulate field conditions and predict project performance.

\section{CONCLUSION}

Management and Control has the highest influence on labour productivity as regards cost, time and quality together from the SEM modelling result with the highest coefficient of $0.85(85 \%)$ followed by workforce at $0.76(76 \%)$ and material $\&$ equipment at $0.69(69 \%)$. This model showed that a solid management, workforce and material logistics structure is key 
to consistent productivity that enhances good project performance.

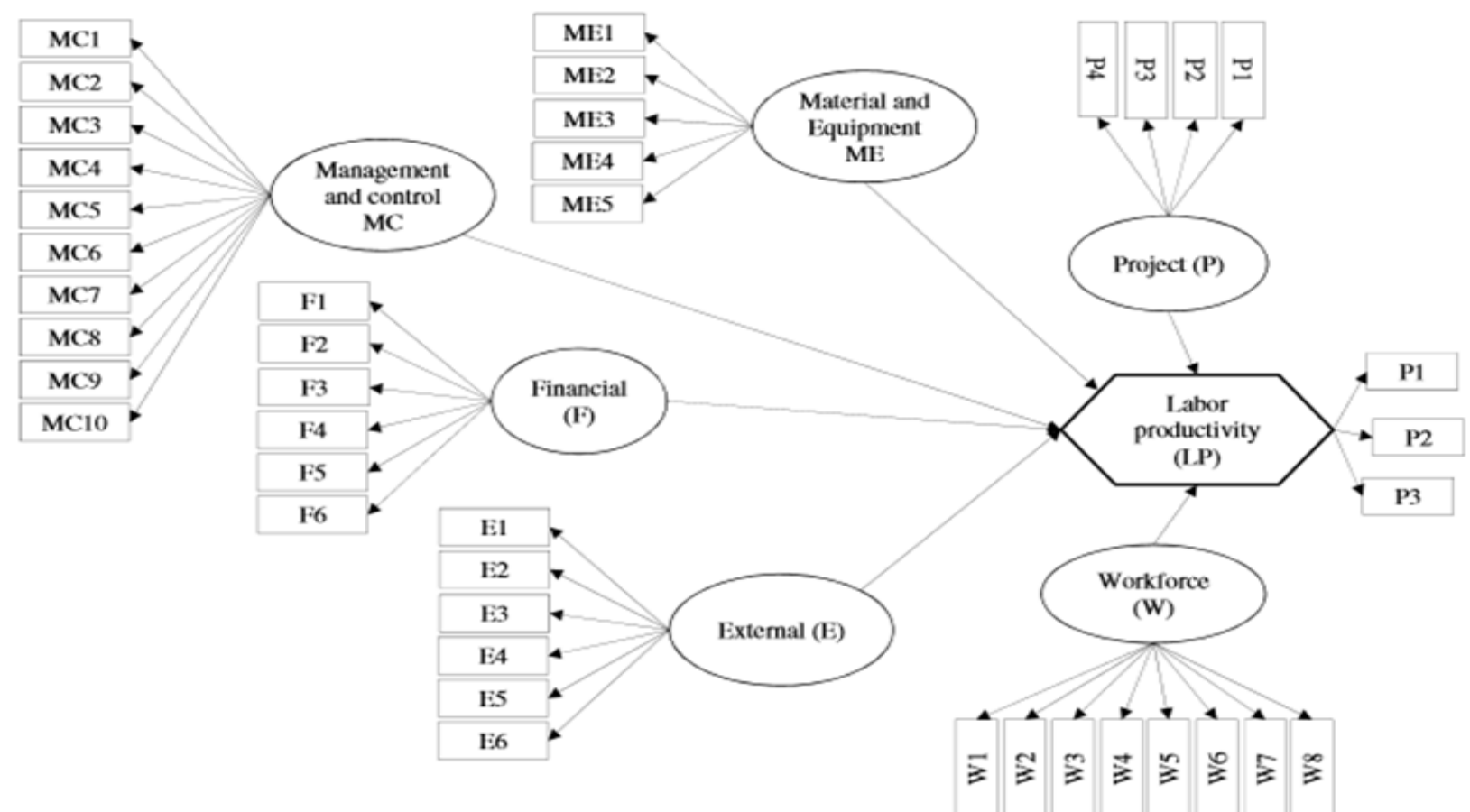

Flow chart of the Labor Productivity Influencing Factors

Fig. 2:

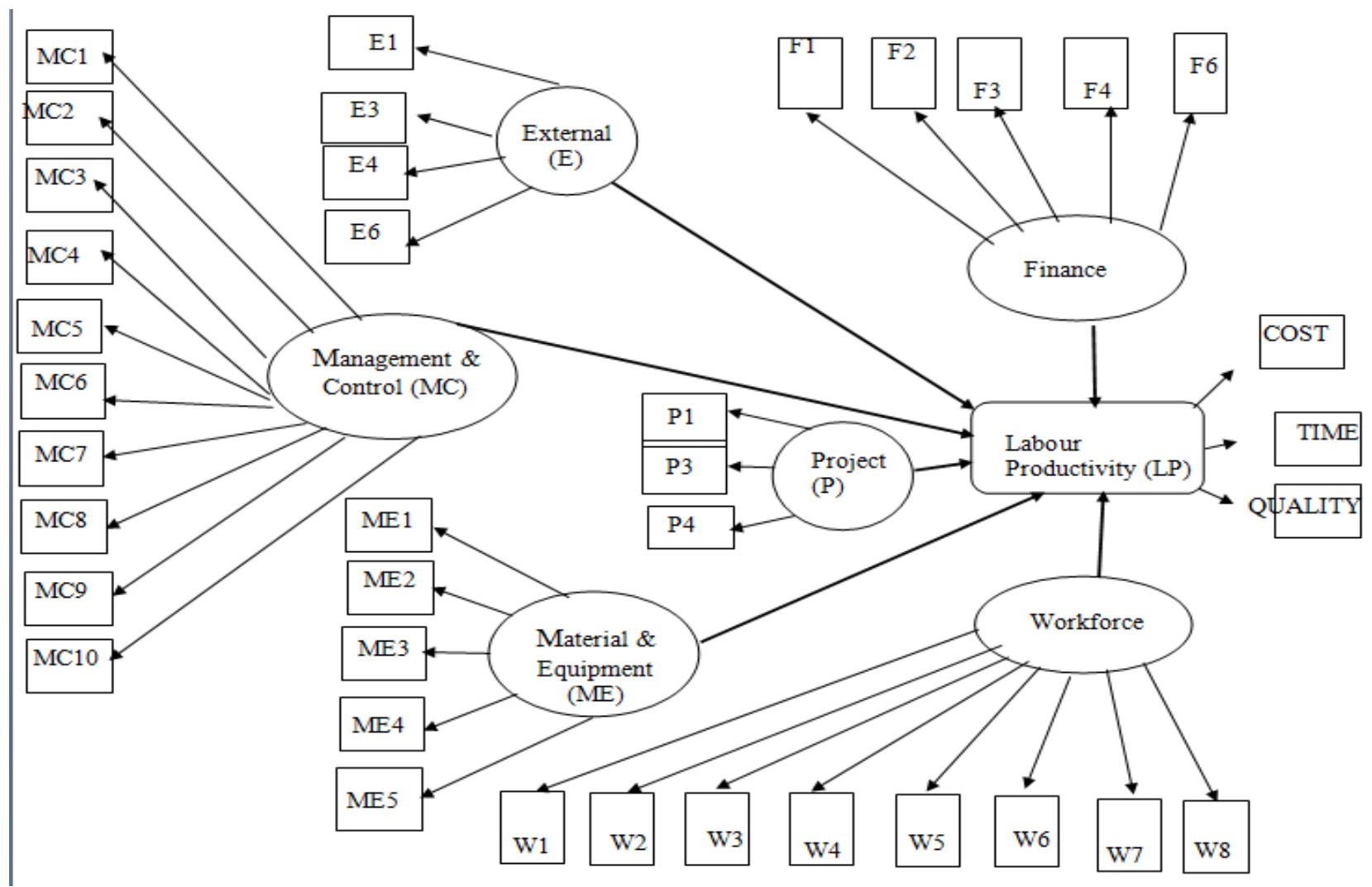

Fig. 3: Final Baseline Model for the SEM ANALYSIS 


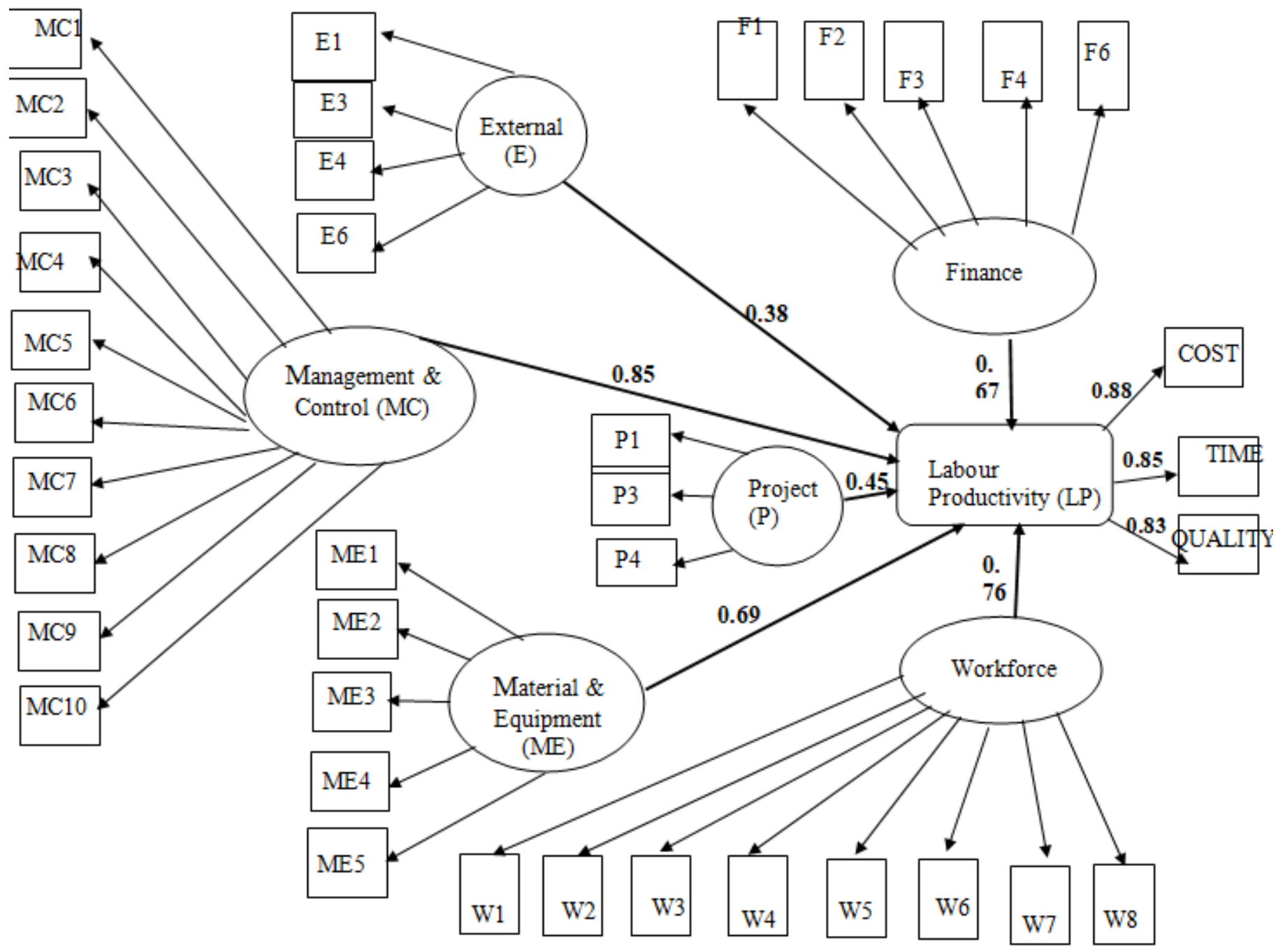

Fig. 4: Structural Equation Model Result

\section{REFERENCES}

[1]. Fagbenle, O. I., Ogunde, A. O., \& Owolabi, J. D. (2011). Factors affecting the performance of labour in Nigerian construction sites. Mediterranean Centre of Social and Educational Research Journal, pp. 251-257.

[2]. Umoru, D., \& Yaqub, O. (2013). Labour productivity and health capital in Nigeria: The empirical evidence. International Journal of Humanities and Social Science, pp. 199-221.

[3]. National Bureau of Statistics, (2016). Nigerian Construction Sector: Summary Report 2010 -2012. Abuja: NBS Office.

[4]. Mbachu, J. I. (2008). Prediction of the Construction Duration of Institutional Building Projects in Nigeria. Nigeria Journal of Construction of Technology and Management, pp. 88-92

[5]. Attar, A. A., Gupta, A. K., \& Desai, D. B. (2012). A Study of Various Factors Affecting Labour Productivity and Methods to Improve It. IOSR Journal of Mechanical and Civil Engineering (IOSR-JMCE), pp. 11-14.

[6]. Adamu, K. J., Dzasu, W. E., Haruna, A., \& Balla, S. K. (2011). Labor productivity constraints in the Nigerian construction industry. Continental Journal of Environmental Design and Management, vol.2 no,1, pp. 9-13.

[7]. Durdyey, S., \& Mbachu, J. (2011). On-site labor productivity of New Zealand construction industry: Key constraints and improvement measures. Australasian Journal of Construction Economics and Building, vol. 11 no 3, pp. 18-33.

[8]. Williams, L. J., Vandenberg, R. J., \& Edwards, J. R. (2009). Structural Equation Modeling in Management Research: A Guide for Improved Analysis. Academy of Management Annals, pp. 543604.

[9]. Kline, R. B. (2005). Principles and Practice of Structural Equation Modelling. New York: Guliford Press.

[10]. Lei, P., \& Wu, Q. (2007). Introduction to structural equation modeling: issues and practical considerations. . Educational Measurement: Issues and Practice, pp. 33-43

[11]. Raj, B. V., Anthony, \& Kothai, P. S. (2014). Improving the Labour Productivity through Other Resources in Construction Field. International Journal of Engineering Research and General Science, Volume 2, Issue 2,pp. 205-213.

[12]. Shashank , K., Sutapa, H., \& Kabindra, N. P. (2014). Analysis of Key Factors Affecting the Variation of Labour Productivity in Construction Projects. International Journal of Emerging Technology and Advanced Engineering(IJETAE), vol.4 no.5, pp. $152-160$

[13]. Agbola, T., \& Olatubara, C. O. (2003). Private Sector Driven Housing delivery in Nigeria: issues, constraints, challenges and prospects. University of Lagos, Department of Estate 
International Journal of Latest Technology in Engineering, Management \& Applied Science (IJLTEMAS)

Volume XI, Issue I, January 2022| ISSN 2278-2540

Management. Lagos: Real Estate Develoers Association of Nigeria (REDAN).

[14]. Ajanlekoko, J. S. (2001). Sustainable housing development in Nigeria- the financial and infrastructure implication. International
Conference on Spatial Information for Spatial Development (pp. 50-64). Nairobi: Kenyan

[15]. Kazaz, A., Ulubeyli, S., Acikara, T., \& Bayram, E. R. (2016). Factors Affecting Labor Productivity: Perspectives of Craft Workers. Elsevier Ltd., Procedia Engineering, 164, pp.28-34. 